\title{
Geographical Distribution of Cacao swollen shoot virus Molecular Variability in Côte d'Ivoire
}

K. Kouakou and B. I. Kébé, Centre National de Recherche Agronomique (CNRA), Programme Cacao, BP 808 Divo, Côte d'Ivoire; N. Kouassi, CNRA, Programme Biotechnologie, Abidjan, Côte d'Ivoire; S. Aké, UFR Biosciences, Université de Cocody, Abidjan, Côte d'Ivoire; C. Cilas, Centre de coopération internationale en recherche agronomique pour le développement (CIRAD), UR 106, 34398 Montpellier, France; and E. Muller, CIRAD, UMR BGPI, Montpellier \begin{abstract}
variability in Côte d'Ivoire. Plant Dis. 96:1445-1450.
The discovery of new outbreaks caused by Cacao swollen shoot virus (CSSV) in Côte d'Ivoire in 2003, when this disease seemed to have been eradicated since the end of the 1950s in that country, casts doubt on the sustainability of Ivorian cocoa production. The aims of this study were, first, to carry out a molecular characterization of CSSV isolates from the main outbreaks in Côte d'Ivoire; second, determine their phylogenetic position in relation to isolates already discovered in Togo and Ghana; and, finally, study their geographical distribution to understand the dispersal of the virus. Additionally, this study was intended to enable the implementation and validation of a polyvalent
\end{abstract}

Abstract

Kouakou, K., Kébé, B. I., Kouassi, N., Aké, S., Cilas, C., and Muller, E. 2012. Geographical distribution of Cacao swollen shoot virus molecular

molecular diagnosis assay for CSSV. Sequences analyses, corresponding to a fragment located at the $5^{\prime}$ end of open reading frame (ORF) 3 of the CSSV genome, revealed three new CSSV groups (D, E, and F) distinct from the A, B, and $\mathrm{C}$ groups already identified in Togo. Only group $\mathrm{B}$ was detected in all the outbreaks, whereas groups $\mathrm{A}$ and $\mathrm{C}$ were not identified in Côte d'Ivoire. In addition, a polymerase chain reaction diagnostic using the ORF3A F/R primer pair was polyvalent, because it enabled the detection of CSSV in $90 \%$ of the plots in all the cocoa regions analyzed by this study.
The sustainability of cocoa production in Côte d'Ivoire, the world's leading producer, has been under threat since the discovery of cocoa swollen shoot disease outbreaks in the Centre West of the country, notably at Bouaflé and Sinfra (12). This disease, which was described for the first time in Ghana by Steven in 1936 (29), is primarily confined to the countries of West Africa. It severely reduces the yields of an affected cocoa tree and kills the tree in under 5 years (23). However, between these two extreme phases (reduced yields and tree death), the leaves gradually turn yellow and fall, then the branches dry out from their tips (die-back). The typical symptoms of the disease are a red vein banding of young leaves, mosaic on older leaves, and, above all, swelling of the orthotropic shoots (23). The pathogen responsible for the disease is Cacao swollen shoot virus (CSSV) belonging to the genus Badnavirus and family Caulimoviridae (15). Natural transmission of the virus is via mealybugs of the family Pseudococcidae in a semipersistent manner (7). The only effective way of controlling swollen shoot disease is to remove infected cocoa trees and their nearest neighbors, then replant with healthy hybrids selected for their partial resistance to the virus (32). However, the cocoa hybrids selected thus far display low resistance against CSSV under conditions of high viral pressure. In fact, not only are CSSV resistance levels low in the cocoa tree $(1,26)$ but, especially, the genetic diversity of CSSV has not yet been taken into account in breeding programs. Six CSSV isolates from Ghana and Togo have been entirely sequenced thus far $(10,19)$ and are genetically structured in three groups: A, B, and C (17).

Swollen shoot disease has always been described as a disease endemic to West Africa, because it has never been reported in

Corresponding author: E. Muller, E-mail: emmanuelle.muller@cirad.fr

Accession numbers: JN606111-JN606244, JN606110, and JQ743334JQ743343.

Accepted for publication 10 May 2012.

http://dx.doi.org/10.1094/PDIS-09-11-0749-RE

(C) 2012 The American Phytopathological Society
South America, the cocoa tree's area of origin. A viral disease causing similar leaf symptoms has been reported in Trinidad (13) but it is not associated with swellings and the disease is no longer being reported (16). The existence of swollen shoot disease in Malaysia and Sri Lanka $(6,22)$ has not been clearly established (34). In Côte d'Ivoire, swollen shoot disease was identified for the first time in 1943 (2) in two major cocoa-growing regions, center-west region (Daloa) and eastern region, on the Ghanaian border (Abengourou and Agnibilékrou). However, most research was undertaken in the east of the country because the disease had a greater impact in that zone. At the time, the Daloa region was not considered to be a major cocoa-producing zone (27) and the few outbreaks displayed less severe symptoms. Consequently, losses attributable to swollen shoot disease were considerable in eastern Côte d'Ivoire, where two forms of the disease were described: the Kongodia form, similar to the New Juaben form in Ghana, which is very virulent, leading to the rapid death of plants within 3 to 5 years, and the benign Sankadiokro form, which has not been found to have an impact on yields (27). Unlike in Ghana, where swollen shoot disease has prevailed for more than 70 years, with the removing of more than 200 million cocoa trees (16), there seems to have been a balance in Côte d'Ivoire since the end of the 1950s between CSSV and Ivorian cocoa growing. That balance can be explained not only by the fact that disease development in those outbreaks was slow but especially by strict application of plant quarantine, leading to the destruction of over 150,000 cocoa trees in that country. Since then, and up to the discovery of outbreak in Bouaflé and Sinfra in 2003 (12), research on swollen shoot disease had been discontinued, because no agriculture service reports mentioned any cases over that long period. In addition, some indigenous reservoir plants of the same family or of families close to that of the cocoa tree, from the order of the Tiliales, displaying or not displaying symptoms similar to those caused by CSSV, naturally harbor a virus $(14,24,33)$ which might lie at the origin of the disease in West Africa. Indeed, the disease can be experimentally transmitted from the species Ceiba pentandra, Cola chlamydantha, C. gigantea, and Adansiona digitata to cocoa seedlings by mealybugs that are vectors of CSSV (25). These plant species may even now be new sources of inoculum. 
The swollen shoot outbreaks discovered in 2003 in Côte d'Ivoire called for a control strategy based on varietal selection, in order to ensure the sustainability of Ivorian cocoa production. However, the planting material needs to be able to resist all the isolates existing in the growing zone, to prevent the resistance from being overcome. Therefore, it was essential to gain knowledge of the genetic variability of the viral isolates involved in the disease in Côte
d'Ivoire, in order to screen planting material prior to replanting new cocoa genotypes. Consequently, the main objectives of our study were to carry out a molecular characterization of CSSV isolates in the main outbreaks in Côte d'Ivoire, and validate a polyvalent molecular diagnosis of CSSV. It more specifically involved detecting the virus in samples using polymerase chain reaction (PCR) diagnosis and new polyvalent primers (18). A phylogenetic

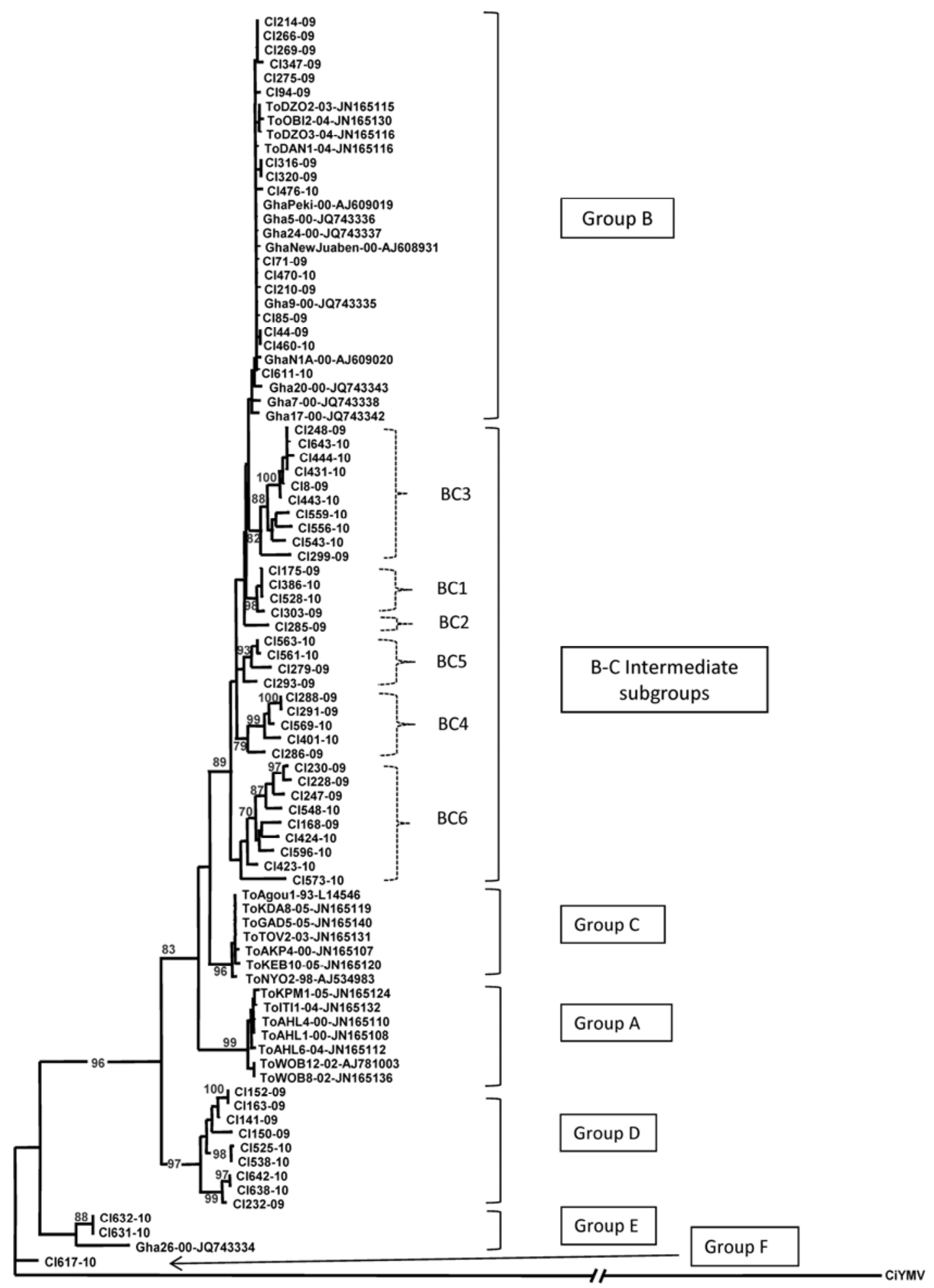

Fig. 1. Phylogenetic tree based on the nucleotide sequences of the $5^{\prime}$ end of open reading frame 3 and constructed with PhyML software $(10)$ with 1,000 bootstrap repeats using the maximum likelihood method (percentage indicated when over 70). Names of the Cacao swollen shoot virus (CSSV) groups A, B, C, D, E, and F along with the six B-C intermediate subgroups are indicated. Only representative isolates of group B, subgroups B-C, and group D are included. CSSV sequences representative of groups A, B, C, and E discovered in Togo and Ghana (19) were used in comparison along with the Citrus mosaic virus sequence (CiYMV; AF347695) used as the outgroup. Names of sequences include the abbreviation of the country ( $\mathrm{Cl}$ for Côte d'Ivoire, Gha for Ghana, To for Togo), the abbreviation of the locality name or a sampling number, and the year of sampling (1993 to 2010, coded as 93 to 10). Names of sequences from Togo and Ghana are followed by their GenBank accession number. 
analysis was also undertaken to compare the sequences of the Ivorian isolates with those of the isolates already obtained from Togo and Ghana and, finally, the geographical distribution of the viral isolates was studied to gain a clearer understanding of the dispersal of the virus in the different outbreaks.

\section{Materials and Methods}

Collection of cocoa leaf samples. The plant material consisted of three to five young leaves per cocoa tree, displaying red vein banding symptoms. The material was taken from 615 cocoa trees spread over 119 plots naturally infected by swollen shoot disease, at a rate of 5 to 10 cocoa trees per plot. This sampling operation covered the main swollen shoot disease outbreaks discovered in Côte d'Ivoire since 2003, in the center-west region (Bouaflé, Sinfra, and Issia outbreaks), along with several outbreaks located in the eastern region of the country, where the disease was first reported in 1946 in the country (Adzope, Akoupé, Agnibilekrou, and Abengourou). All of the samples were dried and stored at room temperature $\left(25^{\circ} \mathrm{C}\right)$. Ten samples from Ghana, collected in 2000 by $\mathrm{S}$. Sackey and extracted by the same method recorded below, were also studied. In addition, in each of the plots sampled in Côte d'Ivoire, the swollen shoot disease symptoms were described.

Total DNA extraction from leaves. DNA was extracted from fresh or dried leaves with the DNeasy Plant Mini Kit (Qiagen) for each isolate. In all, 30 to $100 \mathrm{mg}$ of material was ground in a microcentrifuge tube in the presence of ceramic beads with a Tissuelyser ( Fast prep-24 disrupter; MP Biomedicals).

PCR diagnosis. Two CSSV-specific primer pairs designed at the $5^{\prime}$ end of open reading frame (ORF) 3 from the alignment of CSSV sequences were used for CSSV diagnosis by PCR. The primer pair ORF3CSSV-F/ORF3CSSV-R, designed by Oro et al. (21) before the isolates from Côte d'Ivoire were studied, only took into account isolates from groups $\mathrm{A}, \mathrm{B}$, and $\mathrm{C}$, and amplified a 721- to 724-bp fragment (temperature $=49^{\circ} \mathrm{C}$ ). The primer pair ORF3A-F 5'GTYRTACCRRAYAYYATGATGAC $3^{\prime}$ and ORF3A-R 5'GTT YCCRTTRSYRGAYTCYTCCCATAC $3^{\prime}$ is internal to the previous one and amplifies a 534- to 537-bp fragment (temperature $=49^{\circ} \mathrm{C}$ ) corresponding to positions 1,848 to 2,381 of the DNA complete sequence of CSSV isolate Agou1 (L14546). The latter pair was obtained by aligning the set of CSSV sequences available in 2009, including the CSSV sequences detected in Côte d'Ivoire in the outbreaks in the center of the country and which diverged from the uniform groups A, B, and C. PCR was carried out in a $25-\mu \mathrm{l}$ reaction mixture containing $2 \mu \mathrm{l}$ of undiluted DNA extract, each primer at a final concentration of $0.8 \mu \mathrm{M}$, each dNTP at a concentration of $0.2 \mathrm{mM}$, and $1 \mathrm{U}$ of Gotaq DNA polymerase (Promega Corp.) in the reaction buffer supplied by the manufacturer. Reactions were carried out in a Biometra $\mathrm{T}$ personal thermal cycler using an initial denaturation step at $94^{\circ} \mathrm{C}$ for $2 \mathrm{~min}$; followed by 35 cycles at $94^{\circ} \mathrm{C}$ for $30 \mathrm{~s}, 49^{\circ} \mathrm{C}$ for $30 \mathrm{~s}$, and $72^{\circ} \mathrm{C}$ for $45 \mathrm{~s}$; then a final elongation step at $72^{\circ} \mathrm{C}$ for $10 \mathrm{~min}$.

Cloning and complete sequencing of an isolate from group $D$. As described by Muller and Sackey (19), the abutting primers CI150F259 GATGTACTACCAATGCAACCAAGGTC and CI150R260 CTGCTTGTGGGGGTCGTAGAA able to amplify the full genome of isolate CI152-09 from group D were designed and the resulting 7-kb PCR-amplified fragment was cloned and completely sequenced. The sequence of CI152-09 has been deposited

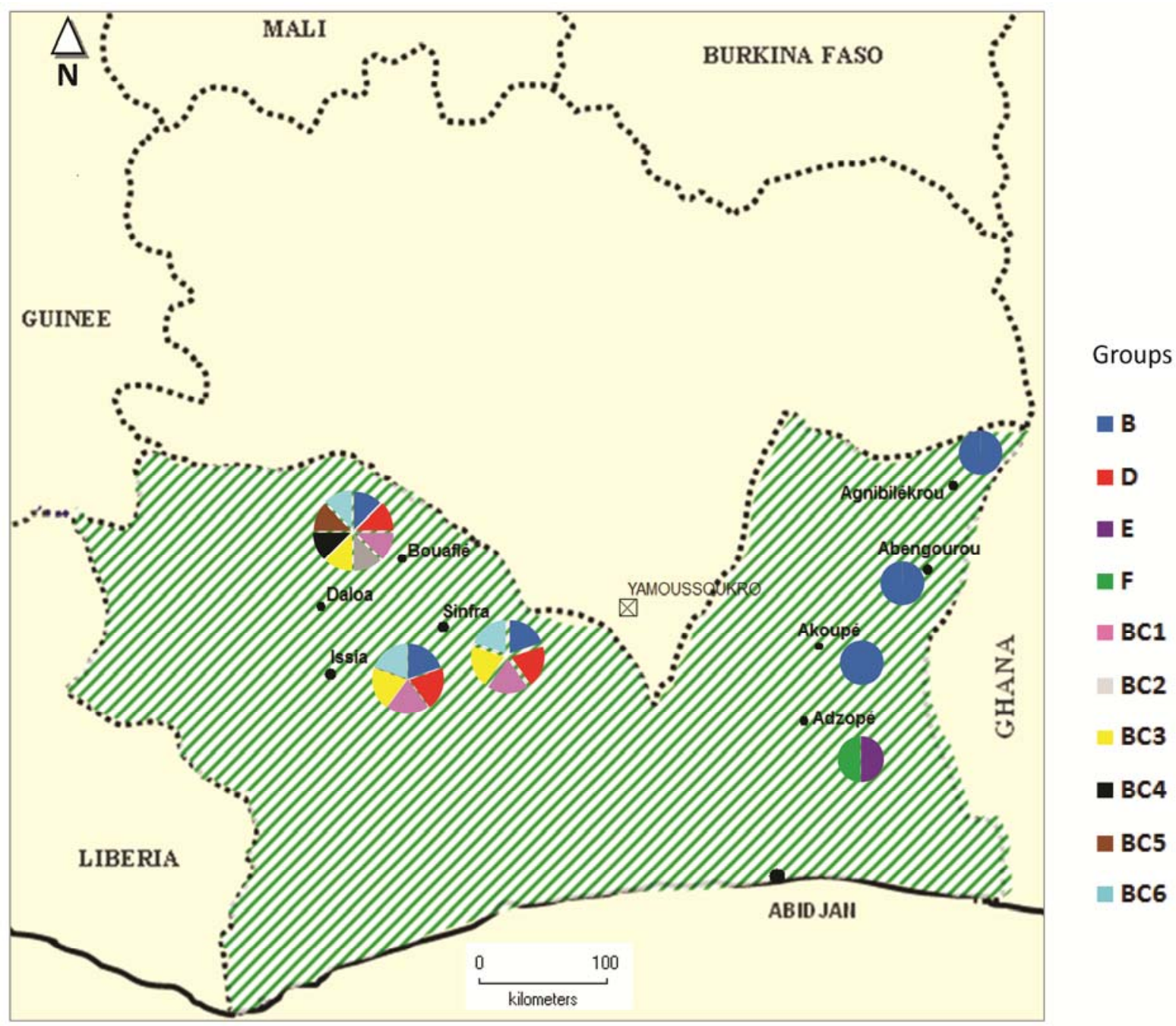

Fig. 2. Spatial distribution of Cacao swollen shoot virus groups of isolates in the different regions of Côte d'Ivoire. 
in the EMBL Sequence database under accession number JN606110.

Sequencing and sequence analysis. As far as possible, two isolates per plot, detected by the PCR diagnosis, were chosen for sequencing. Direct sequencing of the fragments was carried out by Beckman Coulter Genomics (United Kingdom).

The sequences obtained were first edited with Geneious v5.1 (Biomatters Ltd., New Zealand; http://www.geneious.com) and aligned using the Clustal $\mathrm{W}$ multiple alignment algorithm in the Bioedit package (http://www.mbio.ncsu.edu/bioedit/bioedit.html), whereas the phylogenetic tree was constructed with PhyML software (9) with 1,000 bootstrap repeats using the maximum likelihood method.

\section{Results}

PCR diagnosis of CSSV in Côte d'Ivoire. Limits of CSSV isolate detection with the ORF3CSSV-F/R primers. Using primer pair ORF3CSSV F/R on 355 leaf samples from 63 plots, we were only able to detect CSSV in $46.2 \%$ of the samples, though all the leaves analyzed displayed the red vein banding symptoms typical of swollen shoot disease. Various optimizations of PCR diagnosis with primer pair ORF3CSSV-F/R were sought (data not shown) by varying the concentration and volume of the DNA extracts, the number of PCR cycles, and the polymerase enzyme, without any effect on the initial detection percentage obtained. However, CSSV was detected in $73 \%$ of sampled plots, when all plots containing at least one detected sample were considered (Table 1). CSSV was not detected by this assay from 17 plots.

The large number of undetected samples, at $53.80 \%$ despite visible signs of red banding, clearly indicated that primers ORF3CSSV-F/R did not detect all the genetic variability of CSSV in Côte d'Ivoire. In order to by-pass this limitation, primers ORF3A F/R were designed after obtaining the initial results and were used in the rest of this work.

Efficiency of primers ORF3A F/R in detecting CSSV isolates. Primers ORF3A F/R were first tested only on cocoa leaf samples from plots for which no CSSV had been detected with the first primer pair, ORF3CSSV F/R. Of the 17 plots analyzed, the new primers enabled the detection of CSSV in 10 plots. When the seven remaining plots were resampled, CSSV was detected in two plots. The infected samples from those two plots were all detected. This result confirmed that primers ORF3A F/R were more polyvalent than primers ORF3CSSV F/R. The CSSV diagnosis was continued with these new primers on 260 samples from 56 new plots in Côte d'Ivoire and 10 samples from Ghana. CSSV detection amounted to $63.5 \%$ of the samples analyzed (Table 1). When detection was considered on a plot level, the samples from $90 \%$ of the sampled plots could be detected, as opposed to $73 \%$ previously.

Phylogenetic analyses of CSSV isolates. During this study, 134 new partial ORF3 CSSV sequences were obtained from Ivorian isolates and from 10 isolates from Ghana (JQ743334 to JQ743343) and have been deposited in the GenBank database under accession numbers JN606111 to JN606244. CSSV isolates that shared over $85 \%$ nucleotide sequence identity grouped together, forming three new groups $(\mathrm{D}, \mathrm{E}$, and $\mathrm{F})$ which were separate clades from the already known groups A, B, and C (Fig. 1). In addition, six intermediate subgroups were discovered between groups $\mathrm{B}$ and $\mathrm{C}$. In this phylogenetic tree, groups A and $\mathrm{C}$ were very uniform $(>95 \%$ identity between isolates in the same group) compared with group $\mathrm{D}$ and the B-C intermediate subgroups. Group B, for which the standard isolate is the virulent New Juaben from Ghana, also corresponded to a very uniform set where the isolates shared over $95 \%$ identity with each other. However, for group D and the B-C intermediate subgroups (1 to 6 ), higher heterogeneity was found; moreover, the isolates are linked by longer branches, suggesting a faster evolution of the viral sequences. Most of the isolates from Côte d'Ivoire (more than $75 \%$ ) were confined to group B and the $\mathrm{B}-\mathrm{C}$ intermediate subgroups. The remaining $25 \%$ of Ivorian isolates were mostly in group $\mathrm{D}$, while groups $\mathrm{E}$ and $\mathrm{F}$ contained one or two isolates. However, despite the many sequences obtained, no isolates of groups A and C was detected in Côte d'Ivoire. This intergroup difference corresponded to identity percentages well below $80 \%$ (except between B and C, at around $85 \%$ identity).

Spatial distribution of CSSV isolates. The CSSV isolates in Côte d'Ivoire belonged to four of the six groups detected (B, D, E, and $\mathrm{F}$ ) along with the B-C intermediate subgroups. The distribution of the different groups of CSSV isolates in the regions affected by swollen shoot disease in Côte d'Ivoire showed, first of all, that the group B isolates were found in all the outbreaks studied, except at Adzopé (Fig. 2). Then, from east to west of the country, it was seen that all the isolates collected in the different plots of the Moyen Comoé region (Abengourou and Agnibilékrou) contained isolates belonging to group B only. In the Agnéby region in the southeast, the group B isolates were found at Akoupé whereas, at Adzopé, the only isolates of group $\mathrm{F}$ and $\mathrm{E}$ were detected in one of the outbreaks, along with two isolates from group $\mathrm{E}$ in the second outbreak. Finally, in the center-west region, we found isolates from groups B and D at the same time in the Bouaflé, Sinfra, and Issia outbreaks near the Daloa region. The isolates belonging to the B-C intermediate subgroups were mainly detected in outbreaks of Bouaflé and Sinfra, where the disease was discovered in 2003. Generally speaking, the sequences of CSSV isolates from the same plot always belonged to the same group, apart from two plots where an isolate from group B and an isolate from group D were found at the same time. The isolates from Ghana analyzed in this study were mostly in groups B and E.

Analysis of the total genome sequence of isolate CI152-09 belonging to group $\mathbf{D}$. The complete genome sequence of the new CSSV isolate CI152-09, in group D from a center-west outbreak, is $7,203 \mathrm{bp}$ and has the same structure as the previously sequenced viral isolates. The genome is composed of five ORFs: ORF1 comprises 143 amino acids like the ORF1s of the other six isolates already sequenced, ORF2 comprises 139 amino acids, ORF3 comprise 1,872 amino acids, and ORFY comprises 130 amino acids rather than the 131 for the other six isolates already sequenced. ORF $\mathrm{X}$ does not exist but an ORF at the same place as ORF4 detected for the Peki-00 (AJ609019) isolate was detected. This new complete sequence shares 72,71 , and $71.6 \%$ identity with the sequences of the previously obtained isolates Wobe 12 (WOB12-02, AJ781003) from group A, Agou1-93 (L14546) from group C, and Peki-00 (AJ609019) from Group B, respectively.

Field characteristics of the different CSSV groups in Côte d'Ivoire. Different swollen shoot disease symptoms and severity were observed in the analyzed outbreaks. Correlations were sought with the phylogenetic groups that structure the diversity of CSSV isolates. In general, the isolates in groups B and D and B-C intermediate subgroups have caused numerous cocoa tree mortalities in the different outbreaks where they have been identified. In all cases, swellings on the orthotropic shoots and mosaic on mature leaves were observed. The swelling caused by the group D isolates appeared to be more marked and clearly visible compared with those of group B and B-C intermediate subgroups. On the other hand, no shoot swelling, mosaic on old leaves, or cocoa tree deaths were recorded in the plots where isolates of groups $\mathrm{E}$ and $\mathrm{F}$ were identified. This result shows that the isolates of groups B and D and $\mathrm{B}-\mathrm{C}$ intermediate subgroups seemed more aggressive in the field, whereas those of groups $\mathrm{E}$ and $\mathrm{F}$ appeared to be benign. However, there was substantial variability in the symptoms observed depending on the locations for the same group of isolates. Only the red vein banding symptom on young leaves remained the most constant in all the outbreaks sampled.

\section{Discussion}

Polyvalence of the diagnosis. This study, first of all, enabled us to develop polyvalent CSSV diagnosis by designing PCR primers at the $5^{\prime}$ end of ORF3 of the viral genome. The first PCR primers developed to detect isolate Agou 1 from Togo $(10,18)$ had been designed at the $3^{\prime}$ end of ORF3 encoding the replication enzymes reverse transcriptase (RT) and ribonuclease $\mathrm{H}$ (RNase H). These primers were not degenerated and, consequently, were too specific 
to detect all CSSV isolates. In addition, the conserved motifs present in that zone and used to design the primers were common to the retrotransposons identified in large quantities in the cocoa (Theobroma cacao) genome (3) and, if degeneracies were introduced to make them more polyvalent, it promoted false positives (data not shown). The first analyses of swollen shoot outbreaks in Côte d'Ivoire revealed the polyvalence limits of primers ORF3CSSV F/R $(17,21)$ for detecting CSSV. In fact, although they could be used to amplify a fragment at the $5^{\prime}$ end of ORF3, a zone conserved for the existing groups A, B, and C, they could barely detect half of the isolates from the main outbreaks in Côte d'Ivoire. The new primer pair ORF3A F/R, designed taking into account the variability found in the first analyses of the outbreaks in Côte d'Ivoire, made it possible to detect CSSV in the plots that could not be diagnosed previously, even though the disease was present there. They revealed the existence of CSSV for $63 \%$ of the suspect samples and extended the presence of the virus to $90 \%$ of the plots analyzed. The diagnosis developed by Oro et al. (21) using primers designed at the $5^{\prime}$ end of ORF3 was easily made more polyvalent by designing degenerated primers internal to the first primers and significantly improved specific detection of CSSV without generating false positives. Therefore, this part of the genome is a suitable zone for polyvalent CSSV diagnosis. Nevertheless, although it is true that the diagnosis has been improved, it should be noted that a fair proportion of putative CSSV-infected samples were not detected, whereas they displayed characteristic symptoms of swollen shoot disease. However, detection failure may be due to the low concentration of the virus in the leaves and the old age of the leaves. PCR diagnosis of CSSV needs to be further improved, taking into account new whole sequences of group $\mathrm{E}$ and $\mathrm{F}$ isolates, if possible, before it can really be considered and used as an indexing tool. Given the variability already observed in CSSV populations, it will no doubt become difficult to use a single primer pair to detect all CSSV isolates. However, these results are a considerable step forward in CSSV diagnosis because, for the first time, samples from the main cocoa-producing countries (Ghana, Togo, and Côte d'Ivoire) in the endemic zone of West Africa have been analyzed and compared.

Structuring of CSSV biodiversity in Côte d'Ivoire. The results show considerable genetic diversity for CSSV with the existence of six groups that differ considerably from each other. A study of CSSV biodiversity in Côte d'Ivoire based on swollen shoot disease outbreaks is an important event, because such a study had never been undertaken since the disease appeared in 1943. An analysis of CSSV sequences generated by PCR revealed the existence of three new groups of isolates (D, E, and F) never before described in Côte d'Ivoire. Groups D and F appear specific to Côte d'Ivoire, whereas group E also contains isolates from Ghana. The distribution of the isolates and the sample size provided a representative image of CSSV diversity in the center-west region (Marahoué) and the eastern region (Agnéby and Moyen Comoé). The analysis of CSSV molecular diversity is recent, because it only began on some isolates from Togo at the beginning of the $2000 \mathrm{~s}$ (18) and was subsequently extended to different regions of Togo and to certain isolates from Ghana in 2005 (19). That first study of CSSV diversity revealed CSSV structuring in three groups: A, B, and $C$ (17). When the new sequences of isolates obtained at the end of this exploratory study in Côte d'Ivoire were taken into account, it resulted in six groups structuring CSSV genetic diversity, described on the basis of the alignment of the sequences at the $5^{\prime}$ end of ORF3. This highly conserved region of the CSSV genome (19) also appears suitable for analyzing the structuring of viral isolate populations.

At the same time, because we had also been able to amplify fragments from some Ivoirian isolates of the group D and B-C intermediate subgroups in the RT region (data not shown), we were able to confirm similar structuring in groups A, B, C, and D along with B-C intermediate subgroups. Using the $80 \%$ nucleotide identity threshold in the RT/RNase $\mathrm{H}$ domain for discriminating Badnavirus spp., isolates from group A (WOB12-02, Wobe12 collected in 2002, AJ781003) and group D (CI152-09) could be considered as two new species different from the CSSV species comprising Agou1-93 (L14546), NewJuaben-00 (AJ608931), N1A-00 (AJ609020), and Peki-00 (AJ609019) because their sequences share around $75 \%$ sequence identity as well as with sequences of CSSV species from groups B and C $(8,19)$. Because we were still not able to amplify the RT region of the genome of isolates from group $\mathrm{E}$ and $\mathrm{F}$, we cannot definitively conclude the association of these groups with two other CSSV species. These results showed that swollen shoot disease is caused by viruses corresponding to different putative CSSV viral species, of which five were detected and identified by using molecular tests.

The hypothesis of a recombination between different viral isolates to explain the variability observed would be worth investigating but it would mean obtaining whole sequences of the CSSV isolates in the new groups and subgroups.

Geographical differentiation of diversity groups. CSSV genetic variability in Côte d'Ivoire is represented by the identification of four distinct groups (B, D, E, and F) along with the B-C intermediate subgroups diversely distributed in the swollen shoot disease outbreaks analyzed (Fig. 2). In addition, all the sequences from Togo belonged systematically to the very uniform groups A and C and to group B $(19,21)$. Only the isolates of group B were detected in all the outbreaks in the eastern and center-west region of the Côte d'Ivoire; this group is the only one of the molecular groups that is particularly ubiquitous because it has equally been identified in Togo and in Ghana $(19,21)$. In outbreaks in the east, we found a large proportion of group B isolates (notably, all the samples collected at Abengourou and Agnibilékrou), where the disease caused serious damage in the 1940s to 1950s. The Moyen Comoé region (Abengourou and Agnibilékrou) was home to the first cocoa plantations in Côte d'Ivoire in the 19th century (4) and the majority of the plots there are now ageing and composed primarily of the West African Amelonado variety. The plantations of the center-west region, which are more recent and mostly composed of a mixture of varieties (unselected Amelonados and selected cocoa hybrids), display viral isolates belonging to the B-C intermediate subgroups and to the very heterogeneous group $\mathrm{D}$, groups which are absent from the outbreak in the east. In addition, our field observations showed that the isolates of groups B and D and the B-C intermediate subgroups appear to be very aggressive. Therefore, it seems that the introduction and rapid spread of the disease in the center-west region plots is associated with the introduction or appearance of very particular CSSV isolates. This result means that the CSSV situation in the center-west region has become more worrying than it was in 1946 because the damage at that time was negligible.

Consequences of the variability found. This variability in CSSV subdivided in six groups might partly explain the difficulty in finding cocoa hybrids resistant to CSSV, because all the virus isolates used so far in the breeding programs in Ghana $(1,31)$ and Togo (7) were selected according to the contrasting symptoms expressed in the field. It would seem that those symptoms were not particularly discriminant given the six genetic groups obtained. In fact, apart from the standard symptoms of the virulent New Juaben strain, which have been reproduced on the susceptible Amelonado variety (23), the symptoms of swollen shoot disease occur in different combinations in the field, which are difficult to identify with precision depending on the existence or non-existence of young leaves and how far the disease has advanced, particularly because different CSSV groups may exist in the same plot.

A study on the aggressiveness of the different CSSV genetic groups is planned in the greenhouse, to gain better knowledge of their characteristics, even though it is likely that we shall not be able to make an easy correlation between the molecular characterization of the isolates and the symptoms caused. Indeed, the Agou1 and New Juaben/1A isolates from Ghana associated with the same aggressive form of the disease (5) belong to two distinct groups, B and $C$ (19). If the low aggressiveness of the isolates in groups $E$ and $\mathrm{F}$, associated with no cocoa tree deaths, were to be confirmed, 
they could be used in cross-protection tests (20). These different field characteristics of the CSSV groups existing in Côte d'Ivoire demonstrate the complexity (or even virtual impossibility) of identifying a group based on symptoms alone. In addition, it is important to take into account the effect of the cocoa genotype on symptom expression, which is not always easy.

Origin of the emergence or reemergence of CSSV in Côte d'Ivoire. In order to gain a clearer understanding of the most likely origin of the different groups, it is now important to be able to carry out a more exhaustive assessment of the molecular variability of the CSSV populations in Ghana. If, after analyzing the main CSSV outbreaks in Ghana, it can be confirmed that groups D and F are, indeed, only detected in Côte d'Ivoire, this would indicate that the emergence of swollen shoot disease took place at the same time in different countries, including Ghana. Because Ghana was the first country in which CSSV was identified (29), some of the CSSV isolates detected in Côte d'Ivoire might come from Ghana following planting material exchanges between farmers in these two bordering countries. At the moment, the two groups (B and E) that are common to these two countries are present in the east of Côte d'Ivoire, along the border. Second, the spread of the disease in Côte d'Ivoire may be the outcome of using infected planting material to set up plantations. In their move from the old cocoagrowing zone in the east to the new zone in the center-west and west to seek agricultural land (28), farmers may have unknowingly transported infected material or virus-carrying mealybugs. Indeed, most of the growers in Côte d'Ivoire use unselected planting material (11) of often unknown origin.

Even though CSSD is now so widespread in cocoa that other hosts appear to be of limited epidemiological importance (difference in size between cocoa trees and shade trees, difficulty in experimentally reproducing this host jumping, and so on), the exact role of indigenous hosts has to be explored to explain the origin of the different CSSV molecular diversity groups. Several experiments suggest that indigenous trees such as $C$. chlamydantha, $C$. gigantea, Ceiba pentandra, or A. digitata were the original hosts of swollen shoot virus and that the spread to cocoa occurred after the crop was introduced to West Africa at the end of the 19th century $(14,24,25,30)$. In particular, group D, which is only present in the outbreaks of the center-west region, might indicate the possibility of spontaneous emergence of the disease in Côte d'Ivoire from reservoir plants, some of which are used as shade plants in Ivorian cocoa plantations. However, the existence of several host-jumping events is doubtless not the most likely hypothesis for explaining the presence of group B in different countries. The hypothesis that each homogeneous diversity group could originate from a different original host species should be tested if we succeed in amplifying some viral sequences from these alternative indigenous trees.

\section{Acknowledgments}

We thank le Fonds interprofessionnel pour la recherche et le conseil agricole (Côte d'Ivoire), which funded this work on behalf of the cocoa supply chain in Côte d'Ivoire; CNRA (Côte d'Ivoire) and CIRAD (France) for their effective collaboration in carrying out this work and especially for their financial backing; S. Sackey, currently at Legon University (Ghana), who supplied us with leaf samples infected by CSSV in 2000 under collaboration between the Cocoa Research Institute of Ghana and CIRAD; and P. Biggins for reviewing the English of the manuscript.

\section{Literature Cited}

1. Adu-Ampomah, Y., Ollennu, L. A. A., and Adomako, B. 2003. Sources of resistance to the cocoa swollen shoot virus disease. Pages 643-651 in: Proc. 14th Int. Cocoa Res. Conf. Accra, Ghana.

2. Alibert, H. 1946. Note préliminaire sur une nouvelle maladie du cacaoyer le "swollen shoot". Pages 34-43 in: Agronomie Tropicale. Paris.

3. Argout, X., Salse, J., Aury, J. M., Guiltinan, M. J., Droc, G., Gouzy, J., Allegre, M., Chaparro, C., Legavre, T., Maximova, S. N., Abrouk, M., Murat, F., Fouet, O., Poulain, J., Ruiz, M., Roguet, Y., Rodier-Goud, M., BarbosaNeto, J. F., Sabot, F., Kudrna, D., Ammiraju, J. S., Schuster, S. C., Carlson, J. E., Sallet, E., Schiex, T., Dievart, A., Kramer, M., Gelley, L., Shi, Z., Berard, A., Viot, C., Boccara, M., Risterucci, A. M., Guignon, V., Sabau, X., Axtell, M. J., Ma, Z., Zhang, Y., Brown, S., Bourge, M., Golser, W., Song, X., Clement, D., Rivallan, R., Tahi, M., Akaza, J. M., Pitollat, B., Gramacho, K., D’Hont, A., Brunel, D., Infante, D., Kebe, I., Costet, P., Wing,
R., McCombie, W. R., Guiderdoni, E., Quetier, F., Panaud, O., Wincker, P., Bocs, S., and Lanaud, C. 2010. The genome of Theobroma cacao. Nat. Genet. 43:101-108.

4. Braudeau, J. 1969. Le cacaoyer. Maisonneuve et Larose ed. Techniques Agricoles et Productions Tropicales. Paris.

5. Castel, C., Amefia, Y. K., Djiekpor, E. K., Partiot, M., and Segbor, A. 1980. Le swollen shoot du cacaoyer au Togo. Les différentes formes de viroses et leurs conséquences économiques. Café, Cacao, Thé 24:131-146.

6. Crop Protection Compendium. 2002. Cacao swollen shoot virus. CABI Publishing, Wallingford, UK.

7. Dufour, B., Djiekpor, E. K., Paulin, D., and Cilas, C. 1993. Methode de criblage pour la resistance au virus du swollen-shoot: amélioration de la transmission par cochenilles. Page 243 in: Proc. 11th Int. Cocoa Res. Conf. Yamassoukro, Côte d'Ivoire.

8. Fauquet, C., Mayo, M., Maniloff, J., Desselberger, U., and Ball, L. 2005. Virus Taxonomy: Eighth Report of the International Committee on Taxonomy of Viruses. Elsevier Academic Press, San Diego, CA, USA.

9. Guindon, S., and Gascuel, O. 2003. A simple, fast, and accurate algorithm to estimate large phylogenies by maximum likelihood. Syst. Biol. 52:696-704.

10. Hagen, L. S., Jacquemond, M., Lepingle, A., Lot, H., and Tepfer, M. 1993. Nucleotide sequence and genomic organization of Cacao swollen shoot virus. Virology 196:619-628.

11. Hanak-Freud, E., Petithuguenin, P., and Richard, J. 2000. Les champs du cacao. Un défi de compétitivité Afrique-Asie. In: Collection économie et développement. Karthala et CIRAD, eds. France.

12. Kebe, B. I., Kouakou, K., N'Guessan, N. F., Assiri, A. A., Adiko, A., Aké, S., and Anno, A. P. 2006. Le swollen shoot en Côte d'Ivoire: situation actuelle et perspectives. Pages 907-922 in: Proc. 15th Int. Cocoa Res. Conf. San José, Costa Rica.

13. Kirkpatrick, T. W. 1953. Insect pests of cacao and insect vectors of cacao virus diseases. Pages 130-131 in: Cocoa Research 1945-1951. Imperial College of Tropical Agriculture, Trinidad and Tobago.

14. Legg, J. T., and Bonney, J. K. 1967. The host range and vector species of viruses from Cola chlamydantha K. Schum., Adansonia digitata L. and Theobroma cacao L. Ann. Appl. Biol. 60:399-403.

15. Lockhart, B. E. L. 1990. Evidence for a double-stranded circular DNA genome in a second group of plant viruses. Phytopathology 80:127-131.

16. Lockhart, B. E. L., and Sackey, S. 2001. Cacao swollen shoot. Pages 172173 in: Encyclopedia of Plant Pathology. O. C. Maloy and T. D. Murray, eds. Wiley-Interscience, Inc., New Jersey, USA.

17. Muller, E. 2008. Cacao swollen shoot virus. Pages 403-409 in: Encyclopedia of Virology, 3rd ed. B. W. J. Mahy and M. H. V. Van Regenmortel, eds. Elsevier, Oxford

18. Muller, E., Jacquot, E., and Yot, P. 2001. Early detection of Cacao swollen shoot virus using the polymerase chain reaction. J. Virol. Methods 93:15-22.

19. Muller, E., and Sackey, S. 2005. Molecular variability analysis of five new complete Cacao swollen shoot virus genomic sequences. Arch. Virol. 150:53-66.

20. Ollennu, L. A. A., Hughes, J. d'A., and Owusu, G. K. 1996. Mild strain cross-protection of cocoa against cocoa swollen shoot badnavirus. Trop. Sci. 36:116-128.

21. Oro, F., Mississo, E., Okassa, M., Guilhaumon, C., Fenouillet, C., Cilas, C., and Muller, E. 2012. Geographical differentiation of the molecular diversity of Cacao swollen shoot virus in Togo. Arch. Virol. 157:509-514.

22. Peiris, J. W. L. 1953. A virus disease of cacao in Ceylon. Trop. Agric. Trinidad 109:135-138.

23. Posnette, A. F. 1947. Virus diseases of cacao in West Africa, Cacao viruses 1A, 1B, 1C, and 1D. Ann. Appl. Biol. 34:388-402.

24. Posnette, A. F. 1981. The role of wild hosts in cocoa swollen shoot disease. Pages 71-78 in: Pests, Pathogens and Vegetation. J. M. Thresh, ed. Pitman, London.

25. Posnette, A. F., Robertson, N. F., and Todd, J. 1950. Virus disease of cacao in West Africa. V. Alternative host plants. Ann. Appl. Biol. 37:229-240.

26. Posnette, A. F., and Todd, J. McA. 1951. Virus diseases of cacao in West Africa. The search for virus resistant cacao. Ann. Appl. Biol. 38:785-800.

27. Renaud, R. 1957. Distribution of virus disease of cocoa in the Ivory Coast Pages 78-80 in: Report of the 1957 Cocoa Conference. The Cocoa, Chocolate and Confectionary Alliance, London.

28. Ruf, F. 1999. Comment et pourquoi la Côte d'Ivoire produit durablement plus d'un million de tonnes de cacao. Afr. Agric. 268:21-25.

29. Steven, W. H. 1936. A new disease of cacao in the Gold Coast. Gold Coast Farmer 5:122-144.

30. Thresh, J. M. 1991. The ecology of tropical plant viruses. Plant Pathol. 40:324-339.

31. Thresh, J. M., Owusu, G. K., Boamah, A., and Lockwood, G. 1988. Ghanaian cocoa varieties and swollen shoot virus. Crop Prot. 7:219-231.

32. Thresh, J. M., Owusu, G. K., and Ollennu, L. A. A. 1988. Cocoa swollen shoot: an archetypal crowd disease. Z. Pflanzenkrankh. Pflanzenschutz 95:428-446.

33. Tinsley, T. W., and Wharton, A. L. 1958. Studies on the host range of viruses from Theobroma cacao L. Ann. Appl. Biol. 46:1-6.

34. Vos, J. G. M., Ritchie, B. J., and Flood, J. 2003. Fiche de données sur les parasites. Pages 11-58 in: A la découverte du cacao. Un guide stimulant pour la formation des facilitateurs. CABI Biosciences, eds. Wallingford, UK. 